\title{
Zonas de fronteira/ territórios de guerrilha: ou como nos tornamos todos Marcos, Joaquins, Claras e Severinas
}

\author{
Suzana Schmidt Viganó ${ }^{1}$
}

\section{Resumo}

Este artigo pretende ampliar o conceito de ação cultural, colocando-o em diálogo com a análise sociopolítica de Antonio Negri e Michael Hardt e com as investigações sobre os rumos da arte contemporânea. A ação cultural é compreendida como resistência ao estado de guerra total e à pacificação da capacidade criativa, possibilitando-se enquanto atitude de guerrilha.

Palavras-chave: ação cultural; arte e política; produção de subjetividade; arte e guerrilha.

\section{Abstract}

This article proposes to expand the concept of cultural action, making it talk either with the sociopolitical analysis by Antonio Negri and Michael Hardt, as the investigations upon the pathways to the contemporary art. Cultural action is understood as a means of resistance to the total war state and to the pacification of the creative capacities, making it possible as a guerrilla attitude.

Key-words: cultural action; arts and politics; subjectiveness production; arts and guerrilla.

"Hoje a legitimação da ordem global baseia-se fundamentalmente na guerra. Resistir à guerra, e portanto resistir à legitimação dessa ordem global, tornase assim uma tarefa ética comum" (NEGRI, Antonio e HARDT, Michael. Multidão. RJ:Record,2005, p.130)

\section{Análise do território: a ação cultural e o estado de exceção}

Há cerca de dez anos, iniciei minha prática e pesquisa no campo da ação cultural. Trabalhando na periferia sudoeste de São Paulo, buscava naquela época o sentido de uma prática artística, pedagógica e política que possibilitasse a "construção de discursos críticos e o desencadeamento de processos que levassem à própria democratização da cultura" (VIGANÓ, Suzana: 2006, p.17). Entrei em contato com um universo de ações fragmentadas, mas que se fortaleciam nos centros urbanos e oscilavam

\footnotetext{
${ }^{1}$ Suzana Schmidt Viganó é mestre em Teatro-Educação pela Universidade de São Paulo. Autora do livro: "As Regras do Jogo: a ação sociocultural em teatro e o ideal democrático", SP: Hucitec, 2006. Atua como formadora de professores e orientadora de processos artístico-pedagógicos. Foi professora conferencista do curso de Licenciatura em Artes Cênicas da ECA-USP e coordenadora pedagógica do Programa Vocacional, da Secretaria Municipal de Cultura de São Paulo.
} 
entre construções artístico-pedagógicas aliadas a trabalhos comunitários e práticas utilitaristas, realizadas de acordo com a valoração e necessidade da classe hegemônica, empreendedora das ações. Meu principal interesse era questionar a adoção de políticas culturais "úteis", contrastando-as com outros processos mais marginais, que buscavam ser emancipatórios.

Nos últimos 20 anos, as práticas de ação cultural, sejam elas ligadas ao terceiro setor ou ao poder público multiplicaram-se, tanto em movimentos oriundos das classes pobres como das classes médias. Ao longo do tempo, inúmeras ações foram sucateadas, outras foram enfraquecidas em seu poder emancipatório ao serem absorvidas pelo discurso e imaginário da inclusão social, ou pelo desmantelamento das políticas públicas de cultura; enquanto outras ainda tornaram-se "oficiais" ao reproduzir as necessidades hegemônicas de controle e apaziguamento do imaginário, construindo "sujeitos dóceis" (NEGRI:2005, p.84) e "cidadãos úteis." No entanto, resistindo contra os modelos dominantes de produção econômica e social, novas práticas foram criadas, reconfigurando a ação cultural em suas formas, objetivos e identidades.

Procuro neste artigo rever o conceito de ação cultural, ao analisar suas possibilidades em relação ao panorama socioeconômico atual, com o avanço do capitalismo tardio, do processo de globalização, das crises ecológicas, do estado generalizado de guerra e da hegemonia do trabalho imaterial. Que amplitude ganharia a ação cultural, considerando-a em um contexto urbano e metropolitano, como possibilidade de resistência? E como manter-se alerta contra o uso que ainda se faz - e cada vez mais refinadamente - da ação cultural e da prática artístico-pedagógica como instrumentos de pacificação e apaziguamento das mentes, das sensibilidades e dos conflitos sociais?

Antonio Negri e Michael Hardt, em sua análise sobre a ordem política e o poder no atual estágio do processo de globalização e do capitalismo tardio², explicitam as novas formas de soberania, baseadas não apenas nos Estados-Nação, mas também nas instituições supranacionais que os sustentam. Com o poder organizado mundialmente em rede e em hierarquia assimétrica, os mecanismos de controle social e político deixam de se delimitar claramente em conflitos armados pontuais e instituições de segurança pública que apartam da sociedade os excluídos. Abre-se então um estado de exceção permanente, chamado por Negri e Hardt de "estado de guerra global", como instrumento regulador de amplo espectro. Ao aliar-se o poderio militar e policial

\footnotetext{
${ }^{2}$ NEGRI, Antonio e HARDT, Michael, Imperio, RJ: Record, 2001 e Multidão, RJ: Record, 2005.
} 
ao controle político, social, econômico, psicológico e ideológico, em um "complexo vital-militar" (NEGRI: 2005, p.69) gera-se, ao mesmo tempo, destruição e criação ideológica de subjetividade, produtividade e modos de vida.

"Para ter êxito, não é necessário atacar o inimigo diretamente, mas destruir o ambiente, físico e social, que lhe dá sustentação." (NEGRI: 2005, p.89)

A partir do atual estado de guerra total, como se pensar na ação cultural? Considerando-se que esta compreende a criação de interferências no universo da cultura, que possibilitam a singularização de experiências e a geração de bens imateriais, creio que o sentido que ela pode encontrar hoje é o de criação de focos e redes de resistência. Ao produzir novas subjetividades e formas possíveis de vida, a ação cultural enquanto resistência ao estado de guerra total, não se configura como um inócuo instrumento apaziguador de diferenças e conflitos sociais, mas como ações que trazem em si a criatividade, a comunicação e a cooperação como valores fundamentais.

Num estado de guerra, quando as relações humanas estão extremamente fragilizadas e quando parece impossível fazer frente aos mecanismos de controle, a sociedade civil resiste. Atrapalha-se, criam-se redes subterrâneas, silenciosas e criativas de solidariedade. Ampliando o entendimento da ação cultural para o campo sociopolítico, torna-se necessário o confronto da estrutura do poder, criando ações, não de enfrentamento aberto, mas de resistência, que trabalhem no domínio do imaterial, da produção de subjetividade e das relações afetivas, perpassadas pelo sentido da sobrevivência.

Sobrevivência de quê? De valores humanos, que reconsiderem a existência nesse planeta, que reconsiderem as formas de vida criadas nas lutas de poder que levaram a humanidade ao estado atual de exceção, ao contraste extremo das desigualdades sociais, às massas de desempregados e trabalhadores informais, ao apaziguamento e amortecimento das singularidades criativas, à escassez dos recursos naturais e aos modos predatórios de ocupação geográfica e social das grandes aglomerações humanas.

Num estado de guerra não basta conscientizar, não basta criar pequenos espaços de convívio e de debate, é preciso criar perfurações, atacar diretamente na produção de subjetividade, em larga escala, tornar visível a possibilidade de se recriar padrões mentais, estéticos, de comportamento, valores, formas de relações humanas e de produção material e de relação com o ambiente. Para isso, inúmeras ações são necessárias e que se façam não mais diplomaticamente, mas em território de combate. 
A ação cultural deve ser mais uma aliada na luta do homem pela sobrevivência, nas lutas cotidianas dos trabalhadores e na subversão das relações de dominação. Pode agir como resistência ao cruzar campos de conhecimento que são detidos por parcelas privilegiadas da população com a força revolucionária e criativa de quem tem a necessidade de deslocar-se o tempo todo para gerar sobrevivência, e vice-versa.

Em nossa sociedade, a complexidade das relações humanas, de poder, trabalho, afetos, é multidimensional. As relações de opressão são óbvias quando se luta pela sobrevivência. O que não é óbvio é perceber-se como ser criativo, gerador de formas inusitadas de produção imaterial e de renda. Não se trata mais de simplesmente criar indivíduos críticos, mas sim indivíduos para os quais se abre a possibilidade de intuir e de sonhar. Não se trata mais de antepor opressor e oprimido, mas de fazer compreender a multidimensionalidade da experiência de cada um e de todos neste mundo em que habitamos.

\section{Estratégias de Guerrilha: transformar fraqueza em força}

"Os conflitos e as derrotas ao longo da História são o que impulsionam para o futuro o desejo de libertação" (NEGRI: 2005, p.126)

Com os modelos dominantes de produção econômica e social estruturados em rede, recompondo as hierarquias do poder e trazendo a hegemonia do trabalho imaterial $^{3}$ gera-se o sucateamento de algumas formas tradicionais de resistência e ativismo político. A resistência à guerra total e ao poder em rede torna-se mais eficaz ao organizar-se também de maneira dinâmica, flexível e horizontalmente estruturada, tendo a comunicação, a subversão das formas tradicionais e a produção de subjetividade como concepção. É preciso criar resistências que esvaziem o poder dominante, criando zonas limítrofes de vulnerabilidade.

Movimentos expressivos de resistência transformam, mesmo que imperceptivelmente, as estruturas de poder, a curto e longo prazo, pois as obrigam a se reformularem para se manterem operantes. Se as formas da guerra e do poder mudam para fazer frente às estratégias de resistência, então as lutas sociais e ações que se pretendem revolucionárias no campo da cultura podem ser entendidas como movimentos dinâmicos no processo histórico.

\footnotetext{
${ }^{3}$ Segundo Negri e Hardt, trabalho imaterial é todo aquele que gera produtos imateriais, ou seja: conhecimento, informação, comunicação, relações pessoais e afetivas. NEGRI|HARDT:2005, p.149.
} 
Situações de luta, insurgência e subversão só cessariam atingindo-se um equilíbrio na ordem sociopolítica. Mas é possível obter esse equilíbrio em uma sociedade tão complexa como a do capitalismo tardio? Para tal, seria necessário optar por uma tentativa comum, uma escolha consciente em torno de algum ideal realizador de homem e de sociedade. Isto é de fato possível? Ou não seria o embate entre os movimentos de resistência e contrarresistência o que de fato mantém a dinâmica do processo histórico, impulsionando não apenas a produtividade econômica, mas também as relações sociais e a subjetividade, os desejos e ideias, mesmo que nunca amplamente realizados?

A ação cultural, entendida aqui como ação de insurgência e resistência, opera diretamente nessa luta do mais fraco contra o mais forte, aproximando-se então da prática de guerrilha. Atuar com radicalidade nesse campo abre a investigação sobre a síntese entre a ação estética e a ação política. Criam-se assim perturbações nas estruturas de poder, atacando não diretamente o inimigo, mas reconfigurando o próprio espaço de habitação e as relações que ali operam e se estabelecem.

Como na guerrilha tradicional, a ação cultural hoje deve lutar com as armas do mais fraco, operando em território inimigo e em terreno obscuro, surpreendendo em ações pontuais e contundentes, radicalizando no aprendizado e proposição das formas artísticas, a fim de "vencer pelo cansaço". Aproximando-se enquanto forma das instâncias de poder dominantes, utiliza a inteligência da comunicação, revelando indeterminadamente sua presença ou ausência, adotando e transformando estruturas tradicionais de criação e de relação. Abrem-se assim limiares, que permitem, como no ideal zapatista,“mudar o mundo sem tomar o poder” (NEGRI: 2005, p.124).

A ação cultural como guerrilha atua então em uma zona de fronteira, proporcionando movimento entre a apropriação do trabalho imaterial e das formas simbólicas estabelecidas e a ressignificação dessas formas. Investiga como caminhar coletivamente em terrenos maleáveis, fluídos, em zonas de conflito e transformação constante. A partir da percepção da realidade como uma ausência de pontos fixos, propõem-se investigações artístico-pedagógicas, interferências relacionais e espaciais que instiguem novas possibilidades de ser e estar no mundo ou, como diz Bachelard, de se habitar melhor o mundo.

"Aprender a habitar melhor o mundo, em vez de tentar construí-lo a partir de uma ideia pré-concebida da evolução histórica. Em outros termos, as obras já não perseguem a meta de formar realidades imaginárias utópicas, mas procuram constituir métodos de existência ou modelos de ação dentro da realidade existente, qualquer que seja a escala escolhida pelo artista" (BOURRIAUD: 2009, p.18) 


\section{Zonas de fronteira: transição, subversão, fluidez e gozo}

"A experiência da fuga é como um treinamento para o desejo de liberdade" (NEGRI: 2005, p.181)

Tradicionalmente, a cultura é o espaço de estruturação das sociedades na longa duração: é o cultivar, o compartilhar experiências individuais que sedimentam caminhos para práticas coletivas. Na sociedade pós-moderna estruturada em rede, a própria cultura pode ser compreendida como espaço de troca permanente (espaço performático), interstício: fenômeno instável que se materializa fenomenologicamente a cada execução. Ao se tratar de regiões metropolitanas, esse espaço de fronteira é constantemente criado, destruído e recriado. Ao se pensar na cultura contemporânea como fenômeno instável, pensamos na ação cultural como criadora, ou atuante em zonas de fronteira.

As zonas de fronteira são espaços de contradições e possibilidades criativas; lugares ainda não constituídos e em estado de constante transição e permeabilidade, separando ao mesmo tempo em que misturam. As fronteiras são linhas imaginárias e fluidas, ao mesmo tempo em que distinguem o eu e o outro, são lugares vagos e indeterminados, criados pelo resíduo emocional de uma delimitação não natural. São constantemente transgredidas e subvertidas, promovem os encontros migratórios e interculturais, as hibridizações e heterogeneidades.

Vivenciar a realidade pela transicionalidade das zonas intermediárias possibilita a compreensão da vida enquanto relação trans-subjetiva entre universos existenciais. Dessa maneira, encontramos nos processos criativos de fronteira o lugar das práticas revolucionárias, ao se constituírem enquanto territórios ligados ao risco, à inquietação, à capacidade de imaginar e à razão criativa.

"A única finalidade aceitável das atividades humanas é a produção de uma subjetividade que autoenriqueça continuamente a sua relação com o mundo" (GUATTARI: 1992, p.38)

Ao irromper o campo da cultura enquanto performatividade, a ação cultural busca práticas que não sejam apenas representativas ou apaziguadoras, mas construtoras de espaços de contradição que gerem movimento entre os indivíduos e o coletivo.Que no contato entre agentes culturais, comunidades, artistas e a cidade possa-se estabelecer essa zona de transgressão e fricção. $E$ que pela radicalização da experiência criativa e das formas artísticas, a ação produzida pelo confronto entre os lados fronteiriços faça emergir experiências que, como diz Bourriaud, possibilitem decodificar 
relações, criar comportamentos de trabalho, reinventar territórios, reorganizar temporalidades e subverter o cotidiano, ou seja, produzir subjetividade.

Não se trata mais de caminhar com segurança em direção a uma utopia realizadora de sociedade, ou de organizar racionalmente o debate político, mas sim de se caminhar incertamente e fluidamente pelas malhas de uma rede de conflitos, que traça suas linhas de fuga estimulada pela imaginação criadora. Pela radicalização das formas de organização, estruturação e escolhas estéticas dos processos criativos empreendidos em ação cultural, pode-se verticalizar a experiência da fronteira, criando-se e recriando-se novas coerências e significações, ressingularizando as ações sobre o mundo e sobre os próprios indivíduos e comunidades.

\section{Construção de territórios: reconfigurar nosso lugar no mundo}

"Toda obra é modelo de um mundo viável" (BOURRIAUD:2009, p.27);

Hannah Arendt, ao questionar a hegemonia do utilitarismo nas relações sociais, coloca a seguinte pergunta: "para que serve servir?"4. Em tempos de hegemonia da produção imaterial, creio que se coloca uma nova questão: a que serve criar? Quais os sentidos da criação, seja ela em qual campo do conhecimento opere: artístico, filosófico, científico, pedagógico? Quais as possibilidades de ressignificação e ressingularização de territórios existenciais e práticas de controle social que a criação pode trazer como interferência no campo da cultura?

A manipulação dos processos criativos é uma faca de dois gumes, pois atua em um limiar que pode tanto se materializar em ações afirmativas ou subversivas do poder dominante. A ação cultural enquanto resistência possibilita a criação de linhas de fuga: construção de novos circuitos de comunicação, novas formas de colaboração social, novos modos de interação, de singularização dos afetos, novas possibilidades de relações e de convívio, novos campos de exploração do imaginário, o que gera, em si, novas formas de conhecimento.

A radicalização das formas artísticas, por sua vez, em seus meios e modos de produção, pode levar a ação cultural a uma radicalização da sua própria atitude política, ganhando, assim, coerência intrínseca enquanto atividade criativa e produtora de subjetividade. Seu horizonte passa a ser a esfera das interações humanas, decodificando-as, problematizando-as, oferecendo possibilidades de reinventá-las em seus

${ }^{4}$ ARENDT, Hannah. A Condição Humana. RJ: Forense Universitária, 2003 
modos de trabalho e em suas maneiras de vivenciar as realidades temporais e espaciais. Ao trabalhar no aprofundamento do encontro entre singularidades individuais e artísticas, imiscuindo-se por entre o silêncio dos limiares entre individualidades e comunidades e por entre os micro-poderes, criam-se atitudes de guerrilha nas próprias formas de proposição artística.

"A arte contemporânea realmente desenvolve um projeto político quando se empenha em investir e problematizar a esfera das relações (...) A arte não cria representações, nem "se inspira" no tecido social, mas se insere nele, remete a valores transferíveis para a sociedade." (BOURRIAUD: 2009, pp.23-24).

A ação cultural como produção de modos de convívio rompe com processos artísticos, pedagógicos e de produção tradicionais e busca a experiência do comum, criando interferências, produzindo conhecimento a partir do que é compartilhado, desvendando sentidos ao se tomar de surpresa pelo próprio processo. Experiências radicais de convivência e criação artística são empreendidas hoje na região metropolitana de São Paulo, instalando-se, residindo e atuando performativamente em espaços de instituições públicas e de convívio privado ${ }^{5}$. Se várias experiências como essas trouxerem o inusitado para a cidade, para a intimidade dos cidadãos, para as instituições tradicionais de ensino, saúde e lazer, pode-se ressingularizar os lugares, relações e produções simbólicas instituídas. E ao se dissolverem e atacarem novos "lugares-alvos", deslocando-se clandestinamente, focos de resistência seriam criados, multiplicando-se questionamentos, estranhamentos, imaginários e novas possibilidades de produção sobre a realidade.

Experiências artísticas inusitadas buscam radicalizar seus meios e modos de produção e instalam territórios de guerrilha. O conflito entre modos habituais e excepcionais de existir multiplica as singularidades possíveis e abre espaços de reinvenção que abalam as redes de controle hegemônicas. Dessa maneira a cultura pode configurar-se não como espaço de conservação tradicional de práxis sociais e experiências simbólicas, mas também como território maleável, que permite reconfigurar-se a todo (ou qualquer) momento pela criação de linhas de fuga.

Afirma-se assim a ação cultural não como um projeto de inclusão social ou de pacificação da capacidade criativa, mas como observação e reconfiguração das

\footnotetext{
${ }_{5}^{5}$ Pode-se destacar, nesse sentido, o trabalho da II Trupe de Choque, residente no Hospital Psiquiátrico Pinel, em Pirituba e das práticas criativas do Teatro Documentário, ao interferir em espaços íntimos como criação de dramaturgia, atuando no limiar entre realidade e ficção.
} 
práticas sociais através da produção simbólica. Ao deixar de compartimentar as relações pedagógicas, artísticas e de produção de bens imateriais para criar uma síntese ente elas, faz valer a força do trabalho imaterial gerado nas estratégias de sobrevivência e nas relações assim criadas entre homens e mundo. Abandonando lógicas bipolarizadas de entendimento da realidade, busca trabalhar sobre a complexidade da experiência humana. Se "toda obra é modelo de um mundo viável", é no experimentar e confrontar essas "formas-mundo" (BOURRIAUD: 2009, p.28) que se possibilita, como diz Negri, que o outro não se defina em relação a UM, mas que se singularizem na multiplicidade.

"Somos uma multiplicidade de formas singulares de vida, ao mesmo tempo compartilhamos de uma existência comum" (NEGRI:2005, p.172) - e o comum é o que temos de humanidade. A ação cultural encontra assim o seu sentido na fronteira em que consiste o espaço criativo, nas lutas pela sobrevivência e na explosão de singularidades que passam a traçar a malha da cultura como algo sempre maleável e indefinível, apontando para possibilidades múltiplas de se perceber, compreender, estruturar,brincar, contemplar, imaginar, fazer sonhar o mundo que habitamos.

\section{Referências}

Marcos: guerrilheiro zapatista: Marcos é gay em São Francisco, negro na África do Sul, asiático na Europa, palestino em Israel, indígena nas ruas de San Cristóbal, roqueiro na cidade universitária, judeu na Alemanha, feminista nos partidos políticos, comunista no pós-guerra fria, pacifista na Bósnia, artista sem galeria e sem portfólio, dona de casa num sábado à tarde, jornalista nas páginas anteriores do jornal, mulher no metropolitano depois das 22h, camponês sem-terra, editor marginal, operário sem trabalho, médico sem consultório, escritor sem livros e sem leitores e, sobretudo, zapatista no Sudoeste do México. Enfim, Marcos é um ser humano qualquer neste mundo. Tudo que incomoda o poder e as boas consciências, este é Marcos. (Declaração do Subcomandante Marcos, EZLN, 28l03\1994)

Joaquim: criança, 3 anos: mãe, não fui eu quem jogou água no chão. É que ela achou ele tão bonito que quis namorar com ele!

Clara: criança, 3 anos: mãe, vamos fazer uma música de colorir?

Severina: personagem de ficção: Somos muitos Severinosliguais em tudo e na sinala de abrandar estas pedraslsuando-se muito em cima, la de tentar despertarterra sempre mais extintala de querer arrancarlalgum roçado da cinza. (João Cabral de Mello Neto) 


\section{Bibliografia}

BOURRIAUD, Nicolas. Estética Relacional. SP: Martins Fontes, 2009.

FRIEDMAN, Susan. O falar da fronteira, o hibridismo e a performatividade: teoria da cultura e da identidade nos espaços intersticiais da diferença.www.eurozine.com, 2011.

GUATTARI, Félix. Caosmose: um novo paradigma estético. SP: Ed.34, 1992.

HARDT, Michael e NEGRI, Antonio. Multidão: guerra e democracia na era do Império. RJ: Record, 2005.

VIGANÓ, Suzana Schmidt. As Regras do Jogo: a ação sociocultural em teatro e o ideal democrático. SP: Hucitec, 2006. 